\title{
Similarities between human and animal spatial memory: Item and order information
}

\author{
ROBERT H. I. DALE \\ Southeastern Louisiana University, Hammond, Louisiana
}

\begin{abstract}
Human subjects, sitting at the center of a circle of eight lights, were tested on analogues of radial-maze item-recognition (Roberts \& Smythe, 1979) and order-recognition (Kesner \& Novak, 1982) tasks. Subjects in the item-recognition condition saw a list of seven lights, and then the nonlist (eighth) light was tested against the first, fourth, or seventh light from the list. The subjects were required to point toward the nonlist light. Subjects in the order-recognition condition saw a series of eight lights, followed by a test of the first and second, fourth and fifth, or seventh and eighth serial positions. They were asked to point toward the light with the earlier serial position. Subjects' item-recognition serial-position curves exhibited a recency effect with a 0 -sec retention interval (Experiments 1 and 2), and were U-shaped (Experiment 1) or flat (Experiment 2) with a 30-sec retention interval. Subjects' order-recognition serial-position curves were U-shaped at both retention intervals. Subjects' reported mnemonics were, generally, unrelated to their choice accuracy. The results suggest analogous memory processes in animals and humans.
\end{abstract}

Recent research on memory in animals has been dominated by two paradigms: spatial memory research involving radial mazes (Kesner \& Novak, 1982; Olton \& Samuelson, 1976) and forced-choice recognition tasks involving visual patterns or pictures as stimuli (Roberts \& Kraemer, 1981; Wright, Santiago, Sands, Kendrick, \& Cook, 1985). The forced-choice recognition tasks have included both delayed-matching-to-sample (Roberts \& Kraemer, 1984) and serial-probe recognition tasks (Santiago \& Wright, 1984). Such studies have stimulated the development of theories of animal memory that incorporate concepts from human memory research (Kendrick, Rilling, \& Denny, 1986; Roitblat, Bever, \& Terrace, 1984 ) and models of memory that attempt to integrate human and animal data (Nilsson \& Archer, 1985).

One of the major issues in recent animal research, as in human research, is the analysis of the shape of the "serial-position curve"' (Crowder, 1976). Some studies have obtained $U$-shaped serial-position curves, wherein recognition memory is better for the initial items in a list (primacy effect) and the terminal items in a list (recency effect) than for the items in the middle of the list (DiMattia \& Kesner, 1984; Kesner, Measom, Forsman, \& Holbrook, 1984; Kesner \& Novak, 1982; Roberts \& Kraemer, 1981; Sands \& Wright, 1980). Other studies have obtained only a recency effect, with recognition improving toward the end of the list (DiMattia \& Kesner, 1984; Gaffan \& Weiskrantz, 1980; MacPhail, 1980;

This research was supported by grants from the Research and Grants Committee of Southeastern Louisiana University. The author gratefully acknowledges the assistance of C. Gagnon, L. Henkel, C. Jones, and V. Landry in collecting and analyzing the data. Reprints may be obtained from Robert H. I. Dale, Department of Psychology, Southeastern Louisiana University, P. O. Box 690, University Station, Hammond, LA 70402 .
Roberts \& Kraemer, 1984; Roberts \& Smythe, 1979; Thompson \& Herman, 1977).

There have been two main explanations for the varied shapes of these serial position curves. One explanation is an information-processing account based on radial-maze research (DiMattia \& Kesner, 1984; Kesner et al., 1984). The other is an interference-theory model based on forcedchoice recognition of visual stimuli (Santiago \& Wright, 1984; Wright, Santiago, \& Sands, 1984; Wright et al., 1985).

DiMattia and Kesner (1984) allowed rats to visit five arms of an eight-arm radial maze, then gave them a choice between one of those five arms and one of the three unvisited arms. They obtained a recency effect when rats were rewarded for picking the unvisited arm (win-shift), but a U-shaped serial-position curve when rats were rewarded for picking the arm they had just visited (winstay). DiMattia and Kesner argued that rats have a strong tendency to avoid recently visited locations (Fitzgerald, Isler, Rosenberg, Oettinger, \& Battig, 1985; Haig, Rawlins, Olton, Mead, \& Taylor, 1983), so that the winshift task engages automatic processing (Hasher \& Zacks, 1979). With automatic processing, items early in the list of arms receive no extra processing relative to items in the middle of the list, and no primacy effect is obtained (DiMattia \& Kesner, 1984). On the other hand, the winstay task is inconsistent with the animals' hereditary predisposition and engages effortful processing (Hasher \& Zacks, 1979). According to DiMattia and Kesner, this effortful processing is responsible for the appearance of the primacy effect on the win-stay task because the initial items in the list receive more extensive processing than later items (see Atkinson \& Shiffrin, 1968).

Kesner et al. (1984) applied a similar argument to explain the discrepancy between results by Roberts and Smythe (1979, Experiment 3), on the one hand, and Kes- 
ner and Novak (1982) and Kesner et al. (1984) on the other. Roberts and Smythe forced their subjects to choose three, five, or seven arms of an eight-arm radial maze, in a predetermined order, and then forced them to choose between one of the previously visited arms and a previously unchosen arm. They rewarded subjects for choosing the previously unchosen "nonlist" arm, and obtained a recency effect for all three list lengths: Choice accuracy was better for arms visited toward the end of the list. Kesner and Novak (1982) and Kesner et al. (1984) found Ushaped serial-position curves when subjects were rewarded for choosing the earlier arm from pairs made up of the first and second, fourth and fifth, and seventh and eighth arms visited previously during that trial. Kesner et al. argued that Roberts and Smythe's task required automatic processing because it tapped subject's predispositions, whereas Kesner and Novak's serial-order task engaged effortful processing by placing " a sufficient load on the cognitive system" (Kesner et al., 1984, p. 381). Kesner et al. attributed the primacy effect in Kesner and Novak's experiment to this effortful processing.

In contrast to DiMattia and Kesner's (1984) information-processing account of changes in the shape of the serial-position curve on the radial-maze task, Wright, Santiago, and their associates preferred an interference-theory explanation for changes in the shape of the serial-position curve in their serial-probe recognition task with visual stimuli (Santiago \& Wright, 1984; Wright et al., 1984; Wright et al., 1985). In this series of studies, pigeons, rhesus monkeys, and humans were presented with a series of color slides and then were given a choice between an item from the series and a nonlist item. As the retention interval between list exposure and test was increased, subjects first exhibited a recency effect only, then a $U$-shaped curve, and then a primacy effect only. The development of the primacy effect over time was attributed to a dissipation of retroactive inhibition, whereas the decline of the recency effect with longer retention intervals was attributed to the gradual development of proactive inhibition (Wright et al., 1985).

The present experiments were conducted to evaluate both the information-processing (DiMattia \& Kesner, 1984) and interference-theory (Wright et al., 1985) accounts of changes in the shape of the serial-position curve under varied procedures. Because both accounts are based on theories of human memory processes, human subjects were tested on analogues of Roberts and Smythe's (1979) and Kesner and Novak's (1982) radial-maze tasks. The procedural difference between Roberts and Smythe's and Kesner and Novak's experiments corresponds to the distinction between item memory and order memory in the human literature (Healy, 1974, 1982; Maki, Beatty, \& Clouse, 1984; Murdock, 1983). The informationprocessing account of rats' radial-maze behavior would be supported if humans performed similarly to animals on the radial-maze task. If the human serial-position curves differed from those obtained with animals, however, Kesner and Novak's and DiMattia and Kesner's claims of analogous processes in animal and human memory would be difficult to sustain.

Analogies between memory processes in animals and in humans are complicated by the variable nature of the serial-position curve in the human literature. A brief survey of the two most relevant areas of human memory research will demonstrate the difficulty of drawing global analogies between human and animal memory processes, and the desirability of drawing theoretical analogies only when humans and animals have performed similarly under similar procedures. In the human memory literature, Kesner and Novak's (1982) procedure would be considered a relative-recency judgment task (Berch, 1979; Hacker, 1980; Muter, 1979; Yntema \& Trask, 1963) or an orderrecognition procedure (Donaldson \& Glathe, 1969; Murdock, 1968). Data obtained from humans with these procedures are largely inconsistent with Kesner and Novak's U-shaped serial-position curve. Hacker (1980), Murdock (1968), and Muter (1979) obtained recency effects, whereas only Donaldson and Glathe (1969) obtained a U-shaped serial-position curve. On the other hand, Roberts and Smythe's (1979) procedure resembles procedures in which human subjects discriminate between an item from a list and a nonlist item (item-recognition studies). Such studies have obtained U-shaped serial-position curves (Cornell \& Bergstrom, 1983; Donaldson \& Glathe, 1969; Jahnke \& Erlick, 1968; Loftus, 1974; Murdock, 1968), recency effects (Corballis, 1967; Loftus, 1974; Murdock, 1968; Phillips \& Christie, 1977; Shulman, 1970), and flat serialposition curves (Weaver \& Stanny, 1978). Dynamic changes in the shape of the serial-position curve with increased retention intervals (Wright et al., 1985) may have contributed to the variability in these data.

\section{EXPERIMENT 1}

In this experiment, human subjects were tested on an analogue of Roberts and Smythe's (1979) item-recognition procedure, with two retention intervals. The subject sat at the center of a circle of eight lights, which were equally spaced around the perimeter of the circle. A series of seven lights was illuminated, in random order, and then a test was conducted by illuminating two lights simultaneously-a light from the sequence, and the eighth light in the circle. The subject's task was to point to the light in the pair that had not been in the sequence. This item-recognition task differed from those used in most human item-recognition studies in that the subjects were asked to indicate which light was not in the list. Each subject was given 21 trials, with the novel light tested seven times each against the first, fourth, and seventh light in the sequence shown on that trial. Subjects were tested either immediately after the sequence or after a $30-\mathrm{sec}$ delay.

\footnotetext{
Method

Subjects. A total of 32 college students ( 16 male, 16 female) in a general psychology course received course credit for serving as
} 
subjects. The mean age of the subjects was 21.6 years (range 16-34 years). None of the subjects had participated in a similar experiment previously

Apparatus. The apparatus consisted of eight $60-\mathrm{W}$ white incandescent light bulbs mounted at a height of $80 \mathrm{~cm}$ on the backs of identical wooden chairs. The lights were equally spaced at $45^{\circ}$ intervals around the perimeter of a circle of $3.7 \mathrm{~m}$ radius. The lights were connected to a control panel just outside the circle, which the experimenter used to control the sequence in which the lights were turned on. A stopwatch was used to time various intervals during the test session. A loud buzzer (Radio Shack Catalog No. 60-2357) warned the subject that a light was about to be illuminated. The subject sat in a swiveling office chair that could be turned to face any part of the room. The test room was $10.4 \times 7.9 \mathrm{~m}$, with a concrete floor, four doors, banks of fluorescent lights in the ceiling, and assorted tables, chairs, and wall shelves distributed around the edges of the room. The experimenter sat at a desk in one corner of the room.

Procedure. Each subject was told that he/she would be given a series of tests in which a sequence of lights would be turned on, followed by a choice between two lights--one from the sequence and one that was not in the sequence. The subject was told that the correct response was to point to the light that had not been in the sequence. One practice trial was given, involving a sequence of only two lights and response feedback ("Yes, that is correct". "No, it was the other one"). If the subject picked the wrong light, a second practice trial was administered. Testing then began. A trial started with the verbal signal "Are you ready?" and a brief warn ing buzzer, followed by a sequence of seven lights. Each light remained on for $4 \mathrm{sec}$, with an interlight interval of $3 \mathrm{sec}$. The buz zer sounded during each interlight interval. The test was given immediately after the seventh light for subjects in the 0 -sec delay group ( $n=20,8$ male and 12 female) and $30 \mathrm{sec}$ after the seventh light for the 30-sec delay group ( $n=12,8$ male and 4 female) The intertrial interval was $10 \mathrm{sec}$. Each test paired the light that had not been in the sequence with the first, the fourth, or the seventh light from the sequence. The first, fourth, and seventh lights from the sequence were each tested seven times during the 21 trials. Three sets of 22 different sequences ( 21 trials plus a spare trial) were counterbalanced so that each light was used equally often in the tests, and each light was equally often the correct and the incorrect option in a test. Each of the seven possible relative positions of the correct and incorrect test lights (e.g., correct light two steps clockwise from the incorrect light) was used about equally often. The 22nd trial was used only if the experimenter had made an error on one of the first 21 trials. This occurred for 2 subjects.

A memory-strategy questionnaire was administered to each subject after the test session. The questionnaire included two openended questions ("How did you remember the order of the lights?" "Did you use any other memory strategy or plan? Please describe it briefly") separated by five yes/no questions concerning possible strategies ("Did you use any of the following strategies: Remember particular objects near each of the lights? Practice looking at each of the lights during breaks in the experiment? Remember a series of body movements? Just try to remember where each light was without thinking of anything else? Label each light with a number and remember the numbers?" ). The question about numbering was followed by two options ("Did you: a. Label each light with a number, and keep the same numbers for all of the trials? or b. Number the lights with new numbers on every trial, for example, always call the first light that came on \#1?"').

\section{Results and Discussion}

Choice accuracy. Choice accuracy was measured by the percentage of trials on which the novel arm was chosen over the first, fourth, and seventh arms from the sample sequence. Table I shows the mean choice accuracy for all subjects and choice accuracy for each of the selfreported memory strategies (discussed in the next section). Performance was an increasing function of list position with a 0 -sec delay before testing, indicating a recency effect. With a 30-sec delay, a U-shaped serial-position curve was obtained. A two-way analysis of variance indicated that the serial-position effect $[F(2,60)=6.15, p<.01\}$ and the serial position $\times$ delay interaction $[F(2,60)=$ $4.23, p<.05$ ] were statistically significant, whereas the main effect of delay $[F(1,30)=.03]$ was not. Post hoc tests (Newman-Keuls, $p=.05$ ) indicated that the serialposition curves obtained with the 0 -sec and 30-sec delays differed in shape. Choice accuracy at Serial Positions 4 and 7 was similar under both delays, but subjects were more accurate at Serial Position 1 with the $30-\mathrm{sec}$ delay. Within the 0-sec delay, choice accuracy was equal for the tests involving Serial Positions 1 and 4, but higher for the tests involving Serial Position 7. Within the 30-sec delay, choice accuracy was equal for the tests involving Serial Positions 1 and 7, but lower at Serial Position 4. In other words, the post hoc tests confirmed the impression of a recency effect with a 0 -sec delay and a $\mathrm{U}$-shaped serial-position curve with a 30-sec delay.

The subjects tested with a 0-sec delay exhibited a recency effect, as did Roberts and Smythe's (1979) rats when tested immediately after exposure to the sample sequence. Because of the similarity of performance of humans and animals tested on the same item-recognition task, the present data support the argument for similar memory processes in humans and animals. The $U$-shaped serial-position curve obtained with a 30-sec delay was consistent with the interference-theory hypothesis and with data generated in visual-probe recognition tasks (Santiago \& Wright, 1984; Wright et al., 1984; Wright et al., 1985). The interference-theory argument for the development of a primacy effect over time because of a release from retroactive inhibition is especially plausible because choice accuracy at Serial Position 1 was higher after the 30-sec delay than after the 0 -sec delay. It is not clear how an information-processing hypothesis would explain this

Table 1

Percentage Correct Choices on the Item Task in Experiment 1 as a Function of Self-Reported Memory Strategy and Delay

\begin{tabular}{|c|c|c|c|c|c|c|c|c|}
\hline \multirow[b]{4}{*}{ Memory Strategy } & \multicolumn{8}{|c|}{ Delay } \\
\hline & \multirow[b]{3}{*}{$n$} & \multicolumn{3}{|c|}{$0 \mathrm{sec}$} & \multicolumn{4}{|c|}{$30 \mathrm{sec}$} \\
\hline & & \multicolumn{3}{|c|}{ Serial Position } & \multirow[b]{2}{*}{$n$} & \multicolumn{3}{|c|}{ Serial Position } \\
\hline & & 1 & 4 & 7 & & 1 & 4 & 7 \\
\hline Multiple & 1 & 100 & 100 & 100 & 0 & & & \\
\hline Verbal-permanent & 10 & 94 & 94 & 100 & 7 & 100 & 94 & 96 \\
\hline Spatial-motor & 6 & 90 & 88 & 100 & 4 & 96 & 82 & 100 \\
\hline New-number & 2 & 64 & 71 & 100 & 1 & 100 & 71 & 71 \\
\hline Unclassified & 1 & 86 & 100 & 100 & 0 & & & \\
\hline All Subjects & 20 & 90 & 91 & 100 & 12 & 99 & 88 & 95 \\
\hline
\end{tabular}

Note-Subjects chose between a light from Serial Position 1, 4, or 7 in the list and the nonlist eighth light. Choice of the nonlist light was correct. 
increase in choice accuracy at Serial Position 1 after a $30-$ sec delay. The traditional explanation for the primacy effect (Atkinson \& Shiffrin, 1968) involves extra processing during list presentation, not during the retention interval. Even if one invokes extra processing during the 30-sec delay, it is not clear how this could produce an absolute, rather than relative, increase in choice accuracy at Serial Position 1. Presumably, any item available for extra processing during a 30-sec delay would also be available for an immediate recognition test, making choice accuracy at least as high with the 0 -sec delay as with the 30-sec delay.

Memory strategies. The analysis of self-reported memory strategies was conducted to examine how subjects encoded the nominally spatial stimuli in the series of lights, inasmuch as humans can employ verbal codes to remember locations (Bartram \& Smith, 1984; Hirtle \& Mascolo, 1986; Pezdek \& Evans, 1979) and other nonverbal data (McNicol \& Heathcote, 1986). The postexperimental questionnaire was used to categorize the memory strategies subjects used in the experiment. The author assigned subjects to six mutually exclusive categories on the basis of a checklist coding the subjects' responses to the items on the questionnaire. The categories were verbal-permanent, clockface, spatial-motor, newnumber, multiple, and unclassified (see Table 2 for definitions). The verbal-permanent, spatial-motor, newnumber, multiple, and unclassified categories contained $17,10,3,1$, and 1 subjects, respectively (Table 1 ). An analysis of variance compared choice accuracy under the spatial-motor and verbal-permanent strategies, with serial position and delay as factors (see Table 1). The serialposition main effect was significant $[F(2,46)=6.62$, $p<.01]$. Neither of the other main effects nor any of the interactions reached the $p=.1$ level of significance. Although subjects used both verbal and spatial strategies,

Table 2

Memory Strategy Categories

\begin{tabular}{ll}
\hline Strategy & \multicolumn{1}{c}{ Definition } \\
\hline Clockface & $\begin{array}{l}\text { Imagines a clockface or compass. Labels circle } \\
\text { of lights as times on the clock or directions on } \\
\text { the compass. }\end{array}$
\end{tabular}

New-number

Identifies lights with a series of numbers. Specifically mentions assigning new numbers on each trial.

Spatial-motor Remembers locations by visualizing a shape or pattern constructed by joining the lights with lines as they are turned on. No mention of numbers. Remembers a sequence of body movements, or rehearses the route walked.

Verbal-permanent Labels the lights with a fixed set of numbers that is used on every trial, or remembers an object near each light and rehearses the list of objects.

Multiple

Uses strategies in more than one of the categories.

Unclassified Unable to assign subject to any other category. their self-selected mnemonics did not influence their ability to remember the lights.

\section{EXPERIMENT 2}

Experiment 1 indicated a strong similarity between animal and human performance on Roberts and Smythe's (1979) item-recognition task. Experiment 2 was conducted to replicate the results of Experiment 1, and to extend the human/animal analogy to Kesner and Novak's (1982) order-recognition task. Some groups were tested with seven lights followed by a recognition test involving a light from the sequence and the light that was not in the sequence, as in Experiment 1 (item recognition). Other groups were presented with eight lights, followed by recognition tests involving the first and second, fourth and fifth, or seventh and eighth lights from the sequence. In each case, subjects were rewarded for picking the member of the pair that had been presented earlier in the original sequence (order recognition; Kesner \& Novak, 1982). For both the order and the item discrimination, subjects were tested after either a 0 -sec or a 30 -sec delay.

\section{Method}

Subjects. A total of 185 college students ( 69 male, 116 female) in a general psychology course received course credit for serving as subjects. None of the subjects had been in a similar study previously. Their mean age was 20.6 years (range, 17-41 years).

Apparatus. The apparatus was the same as in Experiment 1.

Procedure. Subjects were assigned to groups on a rotating basis, according to the testing schedule. There were 49 subjects ( 30 female, 19 male) in the 0 -sec-delay item group, 43 subjects ( $24 \mathrm{fe}$ male, 19 male) in the 30 -sec-delay item group, 48 subjects (32 female, 16 male) in the 0 -sec-delay order group, and 45 subjects ( 30 female, 15 male) in the 30 -sec-delay order group.

Subjects in the item groups were tested under procedures similar to those used in Experiment 1. After a practice trial with a twolight sequence, they were reminded that they should point to the light in the test pair that was not in the sequence they had just seen on that particular trial. A trial consisted of a "Ready?" signal; seven lights illuminated, one immediately after the other, for 5 sec each; and then a test pair of lights. There was a $0-\mathrm{sec}$ interstimulus interval, and the buzzer did not sound until the seventh light was turned off. Subjects in the 0-sec delay group and the 30-sec delay group waited $0 \mathrm{sec}$ and $30 \mathrm{sec}$, respectively, between the end of the sample sequence and presentation of the test pair. Over 21 trials, the nonlist light was compared seven times with the first, seven times with the fourth, and seven times with the seventh light from the sample sequence.

Subjects in the order groups were given a two-light practice trial and reminded that they were to point to the light in the test pair that had come earlier in the sample sequence on the current trial. Each trial began with a "Ready?" signal, followed by eight lights turned on for 5 sec each, one immediately after the other. The buzzer sounded after the eighth light terminated. Subjects in the 0-sec delay and 30-sec delay groups waited $0 \mathrm{sec}$ and $30 \mathrm{sec}$, respectively, between termination of the eighth light and presentation of the test pair. The test pair included the first and second, fourth and fifth, or seventh and eighth lights from the sample sequence. The subject was required to point to the light in the test pair that had come earlier in the sample sequence. Each pair of serial positions was tested seven times during the 21 trials. 
For both the item and order conditions, counterbalancing of the specific arms involved in the tests was the same as in Experiment 1. For both conditions, correct responses were given the feedback "Good, that is correct," and incorrect responses were given the feedback "No, it was the other one." A 22nd trial was used if the experimenter had made an error on one of the first 21 trials. This occurred for 4 subjects. The memory-strategy questionnaire described in Experiment 1 was administered to each subject after the test session.

\section{Results and Discussion}

Choice accuracy: Item task. Choice accuracy in the item condition was measured by the percentage of trials on which the nonlist light was selected when paired with the first, fourth, or seventh light from the sample sequence. Table 3 shows the mean choice accuracy for all subjects and choice accuracy for each of the self-reported memory strategies (discussed below). A three-way analysis of variance (delay $\times$ sex $\times$ serial position) indicated that the serial-position main effect $[F(2,176)=19.02]$ and the serial position $\times$ delay interaction $[F(2,176)=$ $8.61]$ were significant at the $p=.01$ level. The delay effect $[F(1,88)=0.40]$ and the sex effect $[F(1,88)=0.15]$ did not approach significance, nor did any of the other interactions. Post hoc tests (Newman-Keuls, $p=.05$ ) indicated that, as in Experiment 1, the 30-sec delay group was more accurate than the 0-sec delay group at Serial Position 1, but there was no difference between the groups at Serial Positions 4 and 7. The improvement in choice accuracy at Serial Position 1 with a $30-\mathrm{sec}$ delay will be considered in the General Discussion. Comparing serial positions within groups, there was a clear recency effect under the 0-sec delay: Performance was better at Serial Position 7 than at Serial Position 4, and better at Serial Position 4 than at Serial Position 1. Under the 30-sec delay, there were no differences in choice accuracy across serial positions.

The failure to replicate Experiment 1 by obtaining a $U$ shaped serial-position curve under a 30 -sec delay may have been related to apparently minor differences in the procedures of Experiments 1 and 2. Several visualrecognition experiments with animals (Roberts \&

Table 3

Percentage Correct Choices on the Item Task in Experiment 2 as a Function of Self-Reported Memory Strategy and Delay

\begin{tabular}{|c|c|c|c|c|c|c|c|c|}
\hline \multirow[b]{4}{*}{ Memory Strategy } & \multicolumn{8}{|c|}{ Delay } \\
\hline & \multirow[b]{3}{*}{$n$} & \multicolumn{3}{|c|}{$0 \sec$} & \multicolumn{4}{|c|}{$30 \mathrm{sec}$} \\
\hline & & \multicolumn{3}{|c|}{ Serial Position } & \multirow[b]{2}{*}{$n$} & \multicolumn{3}{|c|}{ Serial Position } \\
\hline & & 1 & 4 & 7 & & 1 & 4 & 7 \\
\hline $\begin{array}{l}\text { Multiple } \\
\text { Verbal-permanent } \\
\text { Spatial-motor } \\
\text { New-number } \\
\text { Clockface } \\
\text { Unclassified }\end{array}$ & $\begin{array}{r}8 \\
11 \\
12 \\
9 \\
5 \\
4\end{array}$ & $\begin{array}{l}96 \\
79 \\
85 \\
75 \\
94 \\
68\end{array}$ & $\begin{array}{l}93 \\
88 \\
95 \\
75 \\
94 \\
79\end{array}$ & $\begin{array}{r}98 \\
96 \\
100 \\
97 \\
97 \\
93\end{array}$ & $\begin{array}{r}10 \\
12 \\
10 \\
4 \\
3 \\
4\end{array}$ & $\begin{array}{l}89 \\
94 \\
96 \\
79 \\
91 \\
79\end{array}$ & $\begin{array}{r}89 \\
88 \\
94 \\
86 \\
100 \\
86\end{array}$ & $\begin{array}{r}90 \\
93 \\
100 \\
89 \\
91 \\
82\end{array}$ \\
\hline All Subjects & 49 & 83 & 88 & 97 & 43 & 90 & 90 & 92 \\
\hline
\end{tabular}

Note-Subjects chose between a light from Serial Position 1, 4, or 7 in the list and the nonlist eighth light. Choice of the nonlist light was correct.
Table 4

Percentage Correct Choices on the Order Task in Experiment 2 as a Function of Self-Reported Memory Strategy and Delay

\begin{tabular}{|c|c|c|c|c|c|c|c|c|}
\hline \multirow[b]{4}{*}{ Memory Strategy } & \multicolumn{8}{|c|}{ Delay } \\
\hline & \multirow[b]{3}{*}{$n$} & \multicolumn{3}{|c|}{$0 \sec$} & \multicolumn{4}{|c|}{$30 \mathrm{sec}$} \\
\hline & & \multicolumn{3}{|c|}{ Serial Position } & \multirow[b]{2}{*}{$n$} & \multicolumn{3}{|c|}{ Serial Position } \\
\hline & & 1 & 4 & 7 & & 1 & 4 & 7 \\
\hline Multiple & 23 & 81 & 62 & 91 & 18 & 70 & 62 & 75 \\
\hline Verbal-permanent & 2 & 71 & 57 & 71 & 6 & 86 & 74 & 74 \\
\hline Spatial-motor & 6 & 86 & 60 & 83 & 4 & 79 & 75 & 75 \\
\hline New-number & 11 & 66 & 73 & 90 & 13 & 78 & 63 & 71 \\
\hline Clockface & 0 & & & & 3 & 95 & 81 & 86 \\
\hline Unclassified & 6 & 67 & 60 & 93 & 1 & 57 & 71 & 57 \\
\hline All Subjects & 48 & 74 & 64 & 89 & 45 & 76 & 66 & 74 \\
\hline
\end{tabular}

Note-Subjects chose between the lights in Serial Positions 1-2, 4-5, or 7-8. Choice of the earlier serial position was correct.

Kraemer, 1984; Sands \& Wright, 1980; Wright et al., 1984) and humans (Wright et al., 1985) and verbal-recall experiments with humans (Glanzer \& Cunitz, 1966; Murdock, 1962) suggest that the shape of the serial-position curve is very sensitive to changes in list length and in the delay between list presentation and testing. In Experiment 1 , the seven lights in the list were presented for $4 \mathrm{sec}$ each, with an interlight interval of $3 \mathrm{sec}$. In Experiment 2, the stimulus duration was $5 \mathrm{sec}$ and the interstimulus interval was 0 sec. Thus the list was presented over a 46sec period in Experiment 1 and a 35-sec period in Experiment 2 . Further research will be necessary to determine whether this apparently small difference in procedure is responsible for the observed differences in the serial-position curves.

Choice accuracy: Order task. For the order condition, choice accuracy was measured by the percentage of trials on which subjects picked the first light, fourth light, and seventh light in the first-second, fourth-fifth, and seventh-eighth test pairs, respectively. Table 4 shows the mean choice accuracy for all subjects and the choice accuracy for each of the self-reported memory strategies (discussed below). A three-way analysis of variance (delay $\times \operatorname{sex} \times$ serial position) indicated that the serial position main effect $[F(2,178)=27.42, p<.01]$ and the serial position $\times$ delay interaction $[F(2,178)=8.91$, $p<.01]$ were significant. None of the other main effects or interactions reached significance, with the sex $\times$ delay interaction $[F(1,89)=3.68, .05<p<.1]$ attaining the lowest probability level. Post hoc analyses (Newman-Keuls, $p=.05$ ) indicated that the 0-sec delay group was more accurate than the 30-sec delay group at Serial Positions 7-8, with no group differences at Serial Positions 1-2 and 4-5. Within the 0-sec delay condition, subjects were more accurate at Serial Positions 7-8 than at Serial Positions 1-2, and more accurate at Serial Positions 1-2 than at Serial Positions 4-5. There was a Ushaped serial-position curve, and the recency effect was stronger than the primacy effect. Within the 30-sec delay group, choice accuracy was equal at Serial Positions 1-2 and 7-8, and accuracy was lower at Serial Positions 4-5 than at the other two pairs. The $30-\mathrm{sec}$ delay condition 
produced a U-shaped serial-position curve, with equal primacy and recency effects. These data are very similar to those obtained in an order-recognition task with rats on the radial maze (DiMattia \& Kesner, 1984; Kesner et al., 1984; Kesner \& Novak, 1982) and further support the analogy between human and animal memory processes.

Memory strategies. The memory strategies used by the subjects were categorized by the author and another researcher (C. Jones) familiar with the classification scheme (Table 2). The two raters agreed on the categories assigned to 167 of the 185 subjects, for an overall interrater reliability of $82 \%$ [167/203; (agreements)/(agreements + disagreements), Neale \& Liebert, 1980]. The subjects over whom disagreements occurred were reassessed and assigned to categories by the author. For the item tests, $18,23,22,13,8$, and 8 subjects were assigned to the multiple, verbal-permanent, spatial-motor, newnumber, clockface, and unclassified categories, respectively. For the order tests, the corresponding numbers were $41,8,10,24,3$, and 7 subjects. The distributions of memory strategies were different under the item and order conditions $\left[\chi^{2}(5)=26.33, p<.001\right]$. On the other hand, the distributions of reported memory strategies were not influenced by the retention interval. Chi-square analyses were conducted after combining the unclassified and clockface categories because of their small frequencies. The distributions of the five resulting categories of memory strategy (multiple, verbal-permanent, spatialmotor, new-number, and unclassified/clockface combined) were not significantly different for the 0 -sec and 30-sec delays, under either the item condition $\left[\chi^{2}(4)=\right.$ $2.22, p>.1]$ or the order condition $\left[\chi^{2}(4)=3.49\right.$, $p>.1]$.

Analyses of variance were conducted to assess choice accuracy on each task as a function of reported memory strategy, serial position, and delay (Tables 3 and 4). The unclassified category was not included in the analyses because its data were not interpretable, and the clockface category was omitted from the order analysis because no subjects used the clockface strategy under the 0-sec delay.

The analysis of variance for the item task indicated that memory strategy (multiple, verbal-permanent, spatialmotor, new-number, or clockface) was an important parameter in this task $[F(4,74)=3.84, p<.01]$. A post hoc analysis (Newman-Keuls, $p=.05$ ) indicated that choice accuracy was lower under the new-number strategy than under any of the other four strategies, all of which produced similar overall performance. Both the memory strategy $\times$ serial position interaction $[F(2,148)=1.89, p=.065]$ and the memory strategy $\times$ delay $\times$ serial position interaction $[F(2,148)=1.91$, $p=.062]$ fell just short of significance at the $p=.05$ level. These marginally nonsignificant interactions involving memory, serial position, and delay suggest that reported memory strategy may exert dynamic influences on the shape of the serial-position curve. However, this conclusion must be made cautiously, because some cells in the memory-strategy analysis of variance contained very few subjects ( $n=3-12$; see Table 3 ). The memorystrategy analysis of variance also obtained a significant main effect of serial position $[F(2,148)=11.94$, $p<.01$ ] and a significant serial position $\times$ delay interaction $[F(2,148)=4.66, p=.011]$, confirming the analysis of variance reported in the preceding section on choice accuracy.

For the order task, only the main effect of serial position $[F(2,150)=8.84, p<.01]$ and the serial position $\times$ delay interaction $[F(2,150)=3.37, p<.05]$ were significant at the $p=.05$ level. There was no effect of memory strategy (multiple, verbal-permanent, spatialmotor, or new-number) on performance $[F(3,75)=.09$, $p>9$, and none of the other main effects or interactions attained the $p=.1$ level of significance. Overall, the memory-strategy analysis for the order task simply confirmed the analysis of variance in the preceding section on choice accuracy.

\section{GENERAL DISCUSSION}

The results of these experiments indicate that meaningful analogies can be drawn between memory processes in humans and in animals, suggesting that models for the retention of item and order information in human memory (Drewnowski, 1980; Grossberg \& Stone, 1986; Hacker, 1980; Murdock, 1976, 1983; Tzeng \& Cotton,1980) might be applicable to the animal domain. However, the nature of these common memory processes is not clear, and neither information-processing theory (DiMattia \& Kesner, 1984; Kesner \& Novak, 1982) nor interference theory (Wright et al., 1985) can account for all of the results.

With a 0-sec delay under the item-recognition procedure, humans exhibited a recency effect similar to those obtained for animals by Roberts and Smythe (1979) and DiMattia and Kesner (1984) on the radial maze and by Wright et al. (1985) with the visual-probe recognition task. This recency effect, with no primacy effect, is consistent with DiMattia and Kesner's (1984) argument that subjects engage in relatively automatic processing (Hasher \& Zacks, 1979) on the item task. However, the data concerning the subjects' self-reported mnemonics are difficult to reconcile with this suggestion of automatic memory processing. Not only did subjects report relying on at least four different strategies, but about $20 \%$ of them reported using multiple strategies.

The improvement in choice accuracy at Serial Position 1 when a 30-sec delay was imposed is consistent with the visual-recognition data of Wright et al. (1985), and suggests that it would be interesting to find out whether rats would show a similar increase in performance if a delay were imposed under Roberts and Smythe's (1979) radialmaze procedure. As discussed under Experiment 1, the absolute increase in choice accuracy with increased retention interval is consistent with interference-theory models (Wright et al., 1985), but is difficult to explain using tradi- 
tional information-processing hypotheses (Atkinson \& Shiffrin, 1968). For example, one might argue that automatic processing occurred with a 0-sec delay, which resulted in minimal memory-processing demands, but that the imposition of a 30-sec delay before testing induced effortful processing. Such an automatic/effortful account (DiMattia \& Kesner, 1984) would accurately predict an improvement in choice accuracy at Serial Position 1 with a 30-sec delay on the item task, although it could not easily explain why this improvement in choice accuracy did not also occur at Serial Positions 4 and 7, or why the subjects in Experiment 2 reported using the same memory strategies under both delays.

On the order-recognition task, a U-shaped serialposition curve was obtained at both 0 - sec and $30-\mathrm{sec}$ delays. According to Kesner's analysis of the animal data (DiMattia \& Kesner, 1984; Kesner et al., 1984), the Ushaped serial-position curve suggests that the order task involves effortful processing. The finding that the proportion of subjects reporting multiple memory strategies increased from $20 \%$ in the item condition to $41 \%$ on the order task also suggests that the order task involves effortful processing. These data augment previous results (Zacks, Hasher, Alba, Sanft, \& Rose, 1984) questioning Hasher and Zacks's (1979) suggestion that humans process temporal-order information automatically.

It is difficult for the interference theory (Wright et al., 1985) to explain the U-shaped serial-position curve obtained with a 0-sec delay on the order task, since this model should predict a recency effect, as was obtained on the item task. The theory cannot account for the Ushaped curve on the basis of the fact that the actual test delay on this task (in order to push the buzzer and switch on the appropriate lights) was about $2 \mathrm{sec}$, rather than the nominal $0 \mathrm{sec}$, because the same delay occurred on the item task. Thus, interference theory fails to predict the different serial-position curves for choice accuracy on the item and order tasks. Information-processing theory (DiMattia \& Kesner, 1984) can account for the different serial-position curves by appealing to the automatic/effortful processing distinction.

The reduction in the recency effect when the 30-sec delay was imposed on the order task is consistent with previous human (Glanzer \& Cunitz, 1966; Wright et al., 1985) and animal (Wright et al., 1984) data. It can be accounted for by both the information-processing (Kesner \& Novak, 1982) and interference-theory (Wright et al., 1985) models. The former model refers to a loss of information about the last few list items from a short-term store (Atkinson \& Shiffrin, 1968), whereas the latter model refers to a gradual development of proactive interference that reduces choice accuracy at the end of the list (Wright et al., 1985).

Finally, a precautionary note is in order concerning interpretation of the self-reported memory strategies. Although it appears from the reported mnemonics that the subjects in the present experiments relied on effortful memory processing (Hasher \& Zacks, 1979), there is no guarantee that the reported strategies reflect the memory processes actually underlying performance on the tasks. In particular, the reported memory strategies had no influence on choice accuracy in Experiment 1, no influence on choice accuracy on the order task in Experiment 2, and only a slight effect on choice accuracy on the item task in Experiment 2 (the new-number strategy was less effective than the others, and there were suggestions of interactions among memory strategy, delay, and serial position). Strong claims about the influence of memory strategies on choice accuracy in the item and order tasks must await experiments in which the memory strategies are under the experimenter's control.

\section{REFERENCES}

Atkinson, R. C., \& Shiffrin, R. M. (1968). Human memory: A proposed system and its control processes. In K. W. Spence \& J. T. Spence (Eds.), The psychology of learning and motivation (Vol. 2). New York: Academic Press.

Bartram, D., \& Sith, P. (1984). Everyday memory for everyday places. In J. E. Harris \& P. E. Morris (Eds.), Everyday memory actions and absent-mindedness. London: Academic Prẹss.

BERCH, D. B. (1979). Coding of spatial and temporal information in episodic memory. In H. W. Reese \& L. P. Lipsitt (Eds.), Advances in child development and behavior (Vol. 13). New York: Academic Press.

Corballis, M. C. (1967). Serial order in recognition and recall. Journal of Experimental Psychology, 74, 99-105.

Cornell, E. H., \& Bergstrom, L. I. (1983). Serial-position effects in infants' recognition memory. Memory \& Cognition, 11, 494-499.

Crowder, R. G. (1976). Principles of learning and memory. Hillsdale, NJ: Erlbaum.

DiMattia, B. V., Kesner, R. P. (1984). Serial position curves in rats: Automatic versus effortful processing. Journal of Experimental Psychology: Animal Behavior Processes, 10, 557-563.

Donaldon, W., \& Glathe, H. (1969). Recognition memory for item and order information. Joumal of Experimental Psychology, 82, $557-560$.

DREwnowskI, A. (1980). Attributes and priorities in short-term recall: A new model of memory span. Journal of Experimental Psychology: General, 109, 208-250.

Fitzgrald, R. E., Isler, R., Rosenberg, E., OttTinger, R., \& BatTIG, K. (1985). Maze patrolling by rats with and without food reward. Animal Learning \& Behavior, 13, 451-462.

GafFan, D., * Weiskrantz, L. (1980). Recency effects and lesion effects in delayed nonmatching to randomly baited samples by monkeys. Brain Research, 196, 373-386.

Glanzer, M., Cunitz, A. R. (1966). Two storage mechanisms in free recall. Joumal of Verbal Leaming \& Verbal Behavior, 5, 351-360.

GrossberG, S., \& Stone, G. (1986). Neural dynamics of word recognition and recall: Attentional priming, learning, and resonance. Psychological Review, 93, 46-74.

HACKER, M. J. (1980). Speed and accuracy of recency judgments for events in short-term memory. Joumal of Experimental Psychology: Human Learning \& Memory, 6, 651-675.

Haig, K. A., Rawlins, J. N. P., Olton, D. S., Mead, A., \& TaYLOR, B. (1983). Food searching strategies of rats: Variables affecting the relative strength of stay and shift strategies. Journal of Experimental Psychology: Animal Behavior Processes, 9, 337-348.

HASHER, L., ZACKS, R. T. (1979). Automatic and effortful processes in memory. Journal of Experimental Psychology: General, 108, 356-388.

HEALY, A. F. (1974). Separating item from order information in shortterm memory. Joumal of Verbal Learning \& Verbal Behavior, 13, 644-655.

Healy, A. F. (1982). Short-term memory for order information. In 
G. H. Bower (Ed.), The psychology of learning and motivation: Advances in research and theory (Vol. 16). New York: Academic Press.

HirTle, S. C., \& MAscolo, M. F. (1986). Effect of semantic clustering on the memory of spatial locations. Journal of Experimental Psychology: Learning, Memory, \& Cognition, 12, 182-189.

JAHNKE, J. C., \& ERLICK, D. E. (1968). Delayed recognition and the serial organization of short-term memory. Journal of Experimental Psychology, 77, 641-647.

Kendrick, D. F., Rilling, M. E., \& Denny, M. R. (Eds.). (1986). Theories of animal memory. Hillsdale, NJ: Erlbaum.

Kesner, R. P., Measom, M. O., Forsman, S. L., \& Holbrook, T. H. (1984). Serial position curves in rats: Order memory for episodic spatial events. Animal Learning \& Behavior, 12, 378-382.

KeSner, R. P., \& Novak, J. M. (1982). Serial position curve in rats: Role of the dorsal hippocampus. Science, 218, 173-175.

LofTUs, G. (1974). Acquisition of information from rapidly presented verbal and nonverbal stimuli. Memory \& Cognition, 2, 545-548.

MacPhail, E. M. (1980). Short-term visual recognition memory in pigeons. Quarterly Joumal of Experimental Psychology, 32, 531-538.

MAKI, W. S., BeATTY, W. W., \& Clouse, B. A. (1984). Item and order information in spatial memory. Journal of Experimental Psychology: Animal Behavior Processes, 10, 437-452.

MCNICOL, D., \& HEATHCOTE, A. (1986). Representation of order information: An analysis of grouping effects in short-term memory. Journal of Experimental Psychology: General, 115, 76-95.

MURDock, B. B., JR. (1962). The serial position effect of free recall. Journal of Experimental Psychology, 64, 482-488.

Murdock, B. B., JR. (1968). Modality effects in short-term memory: Storage or retrieval? Journal of Experimental Psychology, 77, 79-86.

MURDOCK, B. B., JR. (1976). Item and order information in short-term serial memory. Journal of Experimental Psychology: General, 105, 191-216.

MuRDOCK, B. B., JR. (1983). A distributed memory model for serialorder information. Psychological Review, 90, 316-338.

MUTER, P. (1979). Response latencies in discriminations of recency. Journal of Experimental Psychology: Human Learning \& Memory, $5,160-169$.

NeAle, J. M., Liebert, R. M. (1980). Science and behavior: An introduction to methods of research (2nd ed.). Englewood Cliffs, NJ: Prentice-Hall.

Nilsson, L.-G., ARCHER, T. (1985). Perspectives on learning and memory. Hillsdale, NJ: Erlbaum.

Olton, D. S., \& Samuelson, R. J. (1976). Remembrance of places passed: Spatial memory in rats. Journal of Experimental $P_{\text {sychology: }}$ Animal Behavior Processes, 2, 97-116.

Pezdek, K., \& Evans, G. W. (1979). Visual and verbal memory for objects and their spatial locations. Journal of Experimental Psychology: Human Learning \& Memory, 5, 360-373.
Phillips, W. A., \& Christie, D. F. M. (1977). Components of visual memory. Quarterly Journal of Experimental Psychology, 29, 117-133.

RoberTs, W. A., Kraemer, P. J. (1981). Recognition memory for lists of visual stimuli in monkeys and humans. Animal Learning \& Behavior, 9, 587-594.

Roberts, W. A., \& Kraemer, P. J. (1984). Picture memory in monkeys. Canadian Journal of Psychology, 38, 218-236.

Roberts, W. A., \& SMYTHE, W. E. (1979). Memory for lists of spatial events in the rat. Learning \& Motivation, 10, 313-336.

Roitbl.at, H. L., Bever, T. G., \& Terrace, H. S. (Eds.). (1984). Animal Cognition. Hillsdale, NJ: Erlbaum.

SANDS, S. F., \& WIGHT, A. A. (1980). Serial probe recognition performance by a rhesus monkey and a human with 10 - and 20 -item lists. Journal of Experimental Psychology: Animal Behavior Processes, 6, 386-396.

Santiago, H. C., \& Wright, A. A. (1984). Pigeon memory: Same/different concept learning, serial probe recognition acquisition, and probe delay effects in the serial position function. Journal of $E x$ perimental Psychology: Animal Behavior Processes, 10, 498-512.

Shulman, H. G. (1970). Encoding and retention of semantic and phonemic information in short-term memory. Journal of Verbal Learning \& Verbal Behavior, 9, 499-508.

Thompson, R. K. R., \& Herman, L. M. (1977). Memory for lists of sounds by the bottle-nosed dolphin: Convergence of memory processes with humans? Science, 195, 501-503.

Tzeng, O. J. L., \& CotTon, B. (1980). A study-phase retrieval model of temporal coding. Journal of Experimental Psychology: Human Learning \& Memory, 6, 705-716.

Weaver, G. E., \& STanNy, C. J. (1978). Short-term recognition of pictorial stimuli as assessed by a probe recognition technique. Journal of Experimental Psychology: Human Learning \& Memory, 4, 55-65.

Wright, A. A., Santiago, H. C., \& SANDs, S. F. (1984). Monkey memory: Same/different concept learning, serial probe acquisition, and probe delay effects. Journal of Experimental Psychology: Animal Behavior Processes, 10, 513-529.

Wright, A. A., Santiago, H. C., Sands, S. F., Kendrick, D. F., \& Cook, R. G. (1985). Memory processing of serial lists by pigeons, monkeys, and people. Science, 229, 287-289.

YNTEMA, S. B., \& TRASK, F. P. (1963). Recall as a search process. Journal of Verbal Learning \& Verbal Behavior, 2, 65-74.

Zacks, R. T., Hasher, L., Alba, J. W., SANFt, H., Rose, K. C. (1984). Is temporal order encoded automatically? Memory \& Cognition, 12, 387-394.

(Manuscript received August 1, 1986; revision accepted for publication January 12,1987 .) 